\title{
A comparative anthropometric study of the position of the mental foramen in three populations
}

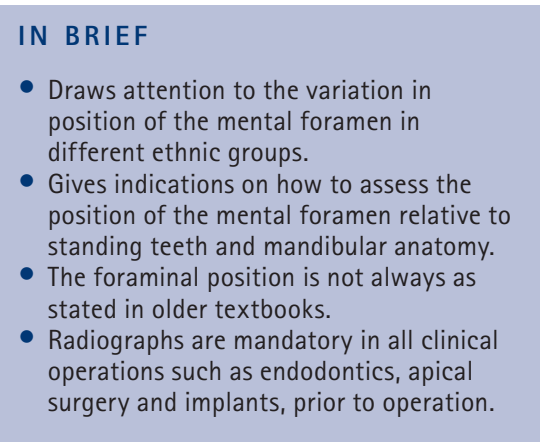

Method The position of the mental foramen was recorded in relation to the mandibular teeth and anatomical landmarks on the mandible in 76 Chinese, 46 European and 33 Indian skulls of known or calculated age at death. One way analysis of variance (ANOVA) with Tukey's test was used to compare the means of the three groups. Results The length of Indian mandibles was significantly smaller than that of Chinese $(p<0.001)$ and European $(p<0.05)$, but there was no significant difference between European and Chinese mandibles ( $p>0.05$ ). The distance from the symphysis menti to the mental foramen was not significant in European and Indian mandibles ( $p>0.05)$, though the latter were significantly smaller than the Chinese $(p<0.001)$. The distance from the mental foramen to the posterior border of the ramus of the mandible was significantly larger in Chinese and European skulls compared to that of Indian $(p<0.01)$, there being no significant difference between European and Chinese ( $p>0.05$ ). There was no significant difference in the relative position of the mental foramen (distance from symphysis menti to the mental foramen divided by the length of the mandible) between the Chinese and Indian mandibles ( $p>0.05$ ) but there was a significant smaller difference between the European and both Chinese and Indian $(p<0.001)$. The modal position of the foramen in the Chinese was in line with the long axis of the second premolar, while the European and Indian between the first and second premolar. Conclusion The notion that the mental foramen lies between the first and second premolars can no longer be accepted. Population differences occur and preoperative radiographs are mandatory.

\section{INTRODUCTION}

The mental foramen is an important anatomical structure representing the termination of the mental canal. Its accurate identification depends on knowledge of its location, this being strategically important for diagnostic and clinical procedures such as the administration of regional anaesthesia, performance of periapical surgery, surgical extractions, endodontics, implant placement and osteotomy. ${ }^{1}$ The reported anatomical position has been inconsistent, with standard anatomy and radiology textbooks containing conflicting statements regarding its position..$^{2-10}$

The modal position was stated to lie between the apices of the permanent

1*2The University of Edinburgh, Edinburgh Postgraduate Dental Institute, Lauriston Place, Edinburgh EH3 9HA, United Kingdom

*Correspondence to: Dr Ario Santini

Email: ariosantini@hotmail.com; Tel: 01315364914

Online article number E7

Refereed Paper - accepted 11 January 2012

DOI: $10.1038 /$ sj.bdj.2012.143

${ }^{\circledR}$ British Dental Journal 2012; 212: E7 mandibular premolars in British, ${ }^{11,12}$ white Americans, ${ }^{13}$ Turkish, ${ }^{14}$ Jordanian ${ }^{15}$ and Nigerian ${ }^{16}$ populations. In Chinese, ${ }^{12}$ Malawian, ${ }^{17}$ Korean, ${ }^{18}$ Asian Indians ${ }^{19}$ and Malay ${ }^{20}$ populations, it lay along the long axis of the second premolar. In black Africans it was reported as most commonly located between the first and second mandibular premolars in Nigerians ${ }^{16}$ and below the second premolar (56\%) or between the second premolar and first molar (36\%) in Kenyan Africans. ${ }^{21}$ In comparison, it was reported to be just posterior to the second premolar in black Americans. ${ }^{22}$

Several authors ${ }^{23,24}$ have alluded to poorly designed studies with ill-defined populations and lack of important parameters such as age at death and age related tooth attrition. Mesial tooth drift following proximal attrition would affect the results when foraminal position is related to teeth and has been offered as a partial explanation of population variation. ${ }^{25}$

The purpose of the present study was to compare the vertical relationship of the mental foramen to standing teeth and the horizontal relationship to the symphysis menti in defined populations of European, Indian and Chinese skulls with known age at death and with similar degrees of tooth attrition.

The null hypothesis is that there is no difference in the vertical relationship of the mental foramen to standing teeth and the horizontal relationship to the symphysis menti in these specified skulls.

\section{MATERIALS AND METHODS}

Skulls from three different populations, Chinese, European and Indian, were obtained from the Turner Collection, The Department of Anatomy, The University of Edinburgh.

The sex and age at death of each of the Chinese skulls was known, having been recorded at the time of acquisition. ${ }^{26}$ The skulls were recorded as being HokienHylam Chinese. The age range was from 16 to 62 years. In attestation of this the collector states 'the age of each individual 
was noted at death and the age, sex and nationality is beyond doubt. ${ }^{26}$

The criteria for inclusion in the present study were that the third molar teeth were fully erupted into the lower arch and that there had been little or no pre-mortem tooth loss or broken or damaged teeth, which would have permitted tooth drift. This resulted in 76 Chinese adult skulls, all known to be over 18-years-old at death, being included in the study.

Using the same criteria, 46 European skulls were obtained with low pre-mortem tooth loss, low caries incidence and similar attrition patterns to the Chinese cohort. These skulls were recorded as being either AngloSaxon (English) or Dark Ages (Scottish).

Thirty-three Indian skulls, also from the University of Edinburgh, Turner Collection, recorded as 'Hindu from River Hoogley, Calcutta', with similar attrition patterns to the Chinese and European groups were included.

The European and Indian skulls were aged using the attrition chart of Miles ${ }^{27}$ allowing them to be placed into two age groups: $<27$ years old at death and $>27$ years old at death. The same criteria as detailed for the Chinese cohort were used for inclusion into the study. All skulls in both European and Indian groups had third molar teeth, fully erupted into the lower arch. As these teeth erupt at about 18 years of age, it was concluded that no juveniles were included in the study.

The position of the mental foramen was recorded in relation to the mandibular teeth, ${ }^{12}$ as lying in line with the long axis of a tooth or interdental space in one of five positions as shown in Figure 1. The position was assessed by holding a transparent, flexible plastic sheet marked with a $\mathrm{T}$ against the lateral aspect of the mandible. The horizontal bar of the $\mathrm{T}$ was aligned with the occlusal plane.

The relationship of the foramen to the body of the mandible was determined in the following, previously used manner. ${ }^{10,11}$ The mandible was placed on a horizontal surface and held by vertical pressure on the second molar teeth (Fig. 2). This is defined as the standard horizontal plane. ${ }^{28}$ A plane parallel to this standard plane was selected by using the height of the most anterior position of the anterior border of the mental foramen. The midline of the symphysis menti was obtained by

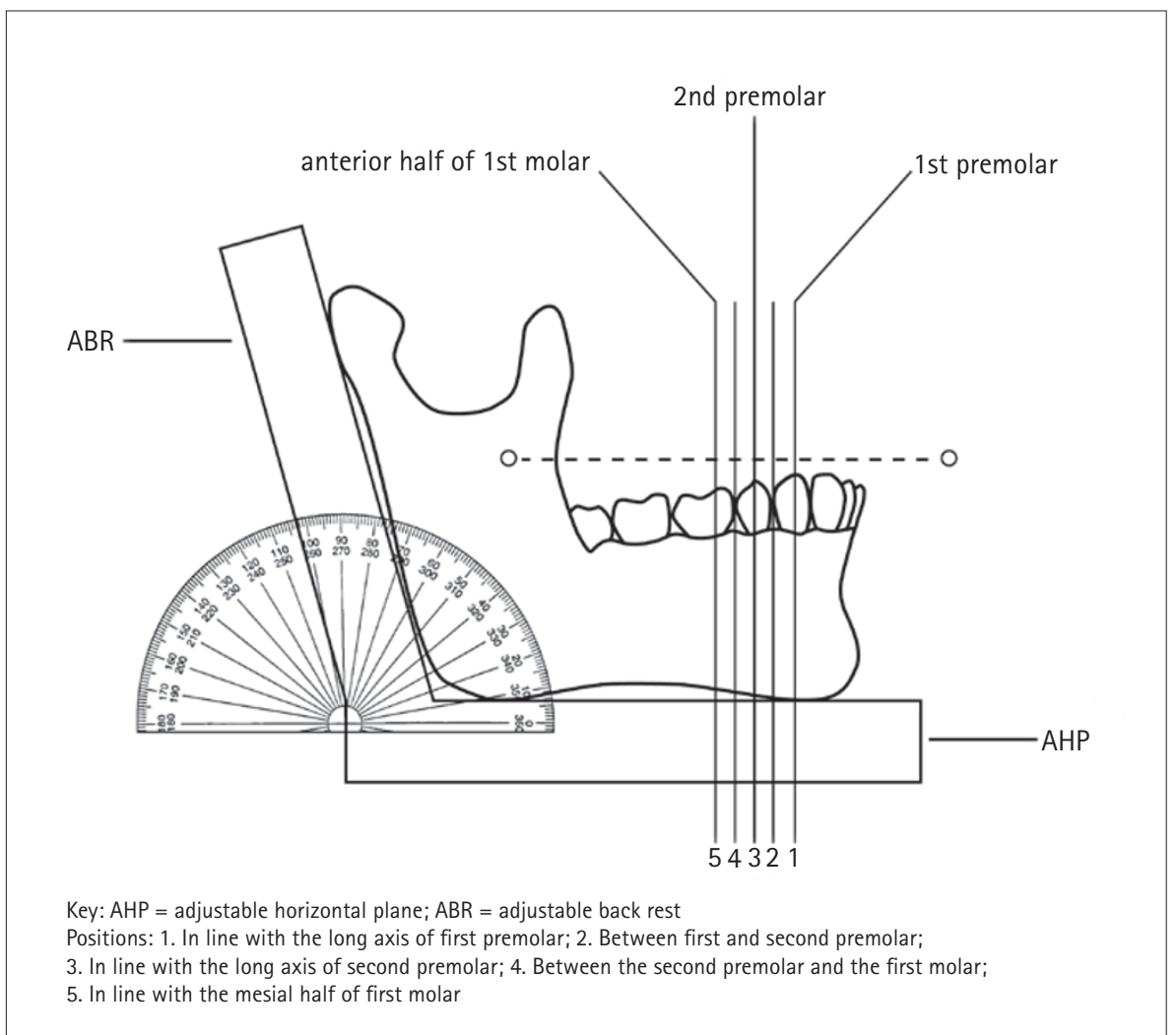

Fig. 1 Assessment of positions of the mental foremen in relationship to standing teeth

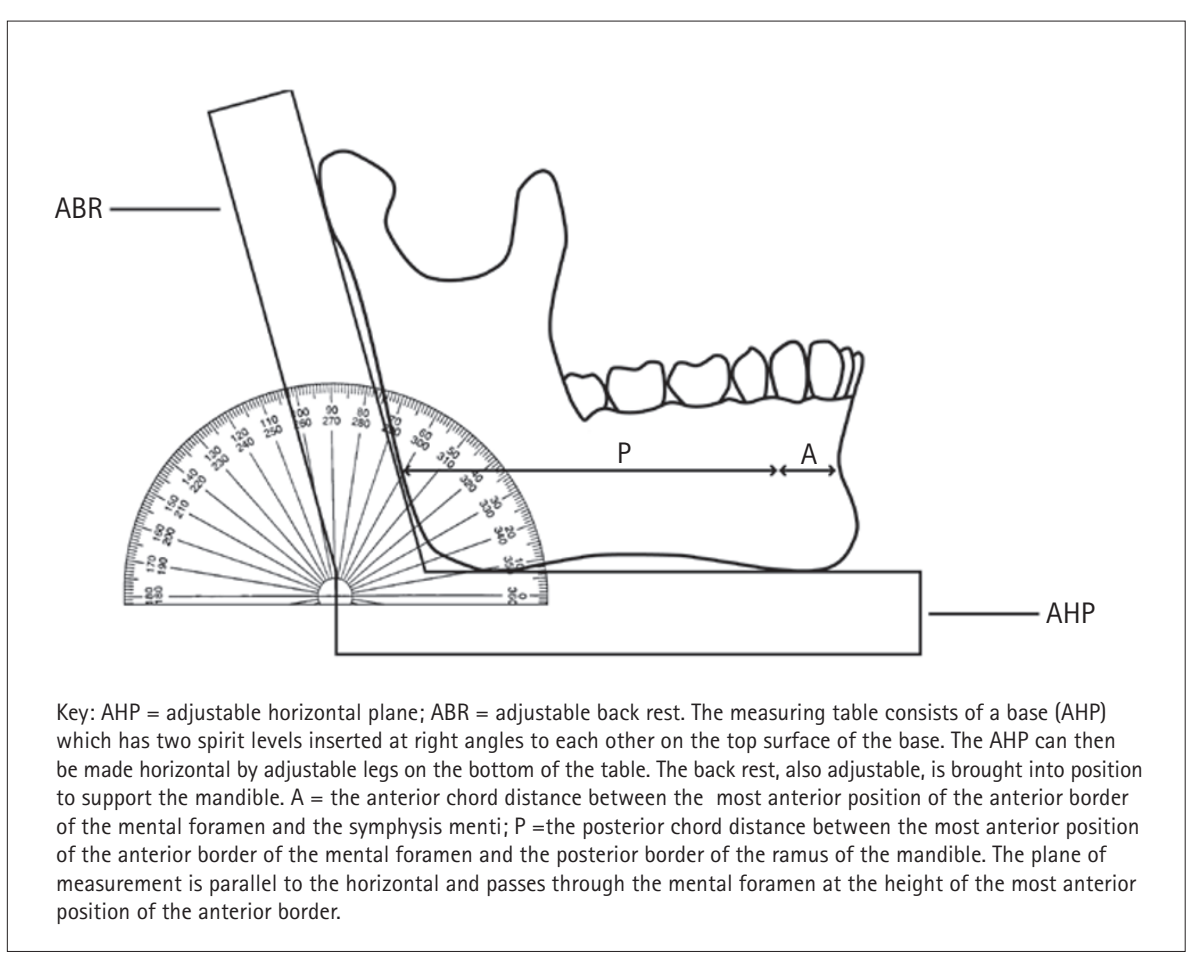

Fig. 2 Assessment of the relationship of the mental foramen to body of mandible

anatomic appreciation and the height from the standard plane to the foramen was indicated at the midline and at the point where this plane crossed the posterior border of the ramus. Calliper measurements were taken of the chord distance from the most anterior position of the anterior border of the foramen to the midline anteriorly at the symphysis menti (chord A), and the distance from the most anterior position of the anterior border of the foramen to the point on the posterior border of the mandible at the level of the selected horizontal line (chord P). The length of the mandible was assessed as the sum of these two chord distances $(\mathrm{A}+\mathrm{P})$. 
Precise definitions of these distances are: $\mathrm{A}=$ the anterior chord distance between the most anterior position of the anterior border of the mental foramen and the symphysis menti; $\mathrm{P}=$ the posterior chord distance between the most anterior position of the anterior border of the mental foramen and the posterior border of the ramus of the mandible. The plane of measurement is parallel to the horizontal and passes through the mental foramen at the height of the most anterior position of the anterior border. The relative position of the mental foramen is given by $\mathrm{A} / \mathrm{A}+\mathrm{P}$.

\section{Statistical tests}

The data from all three groups showed a Gaussian distribution (Kolmogorov Smirnov test) and similar standard deviation (Bartlett's test). This allowed the use of one way analysis of variance (ANOVA) to compare the means of the three groups. Where the overall $p$ value for one-way ANOVA was $p<0.05$, Tukey's test was performed for specific pairwise post hoc mean comparisons.

\section{Power test}

The sample sizes used had a 99\% power to detect a difference between means of $1.50 \mathrm{~mm}$ with a significance level (alpha) of 0.05 (two-tailed).

Statistical analysis was performed using the statistical package Minitab 15 (Minitab Inc, State College, PA, USA).

The digital callipers (Tresna SR44, Guilin Guanglu Measuring Instrument Co., Ltd, Guangxi Province, China) used in this study have an accuracy of $\pm 0.02 \mathrm{~mm}$ per $100 \mathrm{~mm}$, a resolution of $0.01 \mathrm{~mm}$, measuring speed of $\leq 1.5 \mathrm{~m} / \mathrm{s}$, storage temperature of $-10^{\circ} \mathrm{C}$ to $+60^{\circ} \mathrm{C}$, relative humidity of $<80 \%$ and measured up to 2 decimal points of $\mathrm{mm}$. Therefore all data were recorded to two decimal places and all measurements made at $24-25^{\circ} \mathrm{C}$ and $50-55 \%$ of relative humidity as measured by temperature and humidity data logger (USB-502, Measurement Computing Corp, Norton, MA, USA).

\section{RESULTS}

Positions of mental foramen relative to standing teeth and the modal positions are shown in Table 1.

The anthropometric measurements ( $\mathrm{mm}$, SD) are given in Table 2a and TukeyKramer multiple mean comparisons test results in Table $2 \mathrm{~b}$.

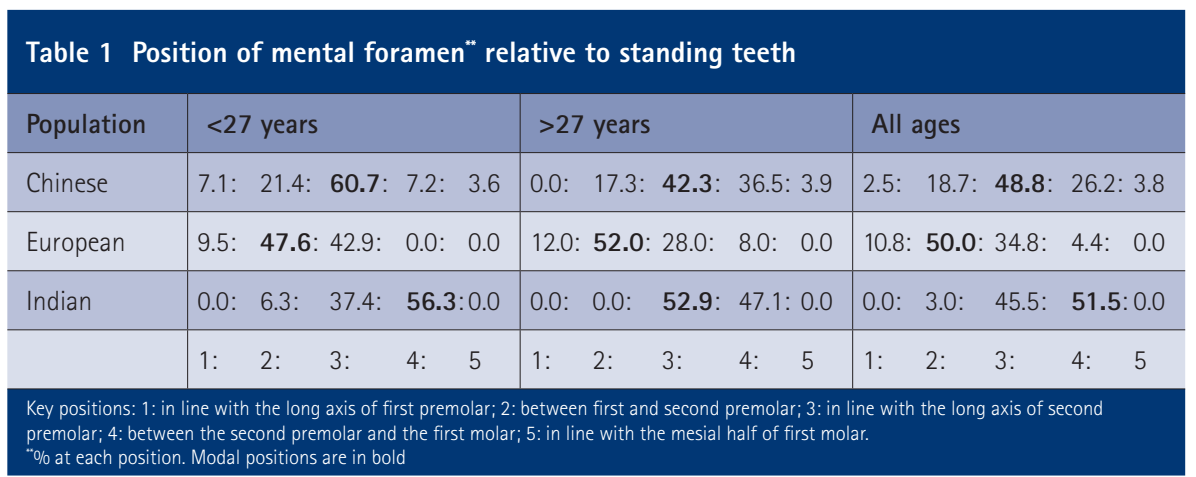

Table 2a Mandibular anthropometric measurements (in mm: mean [SD])

\begin{tabular}{|l|l|l|l|}
\hline Measurement & Chinese & European & Indian \\
\hline MF to SM (A) & $27.97[1.66]^{1}$ & $25.89[2.04]^{1}$ & $26.35[1.81]^{1}$ \\
\hline MF to PB (P) & $70.68[3.95]^{2}$ & $71.80[4.35]^{2}$ & $67.97[4.85]$ \\
\hline Length of mandibles (A+P) & $98.65[4.74]^{3}$ & $97.69[5.40]^{3}$ & $94.32[5.99]$ \\
\hline Relative position (A/A+P) & $0.28[0.01]^{4}$ & $0.26[0.01]$ & $0.28[0.01]^{4}$ \\
\hline $\begin{array}{l}\text { One way analysis of variance. Same superscript numbers indicate no significant difference in horizontal groups. } \\
\text { MF = mental foramen; SM = symphysis menti; PB = posterior border of ramus of mandible }\end{array}$
\end{tabular}

\section{Table $\mathbf{2 b}$ Tukey-Kramer multiple mean comparisons test}

\begin{tabular}{|c|c|c|c|}
\hline \multirow{2}{*}{ Comparison } & \multicolumn{2}{|c|}{$95 \%$ confidence interval } & \multirow{2}{*}{$p$ value } \\
\hline & From & To & \\
\hline Chinese A - European A & 1.268 & 2.892 & $p<0.001$ \\
\hline Chinese A - Indian A & 0.715 & 2.525 & $p<0.001$ \\
\hline European A - Indian A & -0.1 .442 & 0.522 & $p>0.05^{\circ}$ \\
\hline Chinese P - European P & -3.271 & 1.031 & $p>0.05^{\circ}$ \\
\hline Chinese $P$ - Indian P & 0.356 & 5.064 & $p<0.05$ \\
\hline European P - Indian P & 1.476 & 6.184 & $p<0.001$ \\
\hline Chinese $A+P$ - European $A+P$ & -1.383 & 3.303 & $p>0.05^{\circ}$ \\
\hline Chinese $A+P-$ Indian $A+P$ & 1.721 & 6.939 & $p<0.001$ \\
\hline European $\mathrm{A}+\mathrm{P}-$ Indian $\mathrm{A}+\mathrm{P}$ & 0.539 & 6.201 & $p<0.05$ \\
\hline Chinese $A / A+P-$ European $A / A+P$ & 0.011 & 0.019 & $p<0.001$ \\
\hline Chinese $A / A+P-$ Indian $A / A+P$ & -0.004 & 0.006 & $p>0.05^{\circ}$ \\
\hline European $A / A+P-I n d i a n A / A+P$ & -0.019 & -0.009 & $p<0.001$ \\
\hline
\end{tabular}

Each population group was divided into two cohorts, one less then 27 years of age at death and one greater than 27 years of age at death and a combination of all ages.

When the <27-year-old cohort was compared with $>27$-year-old cohort there was no significant difference in chords $\mathrm{A}, \mathrm{P}$, or $\mathrm{A} / \mathrm{A}+\mathrm{P}$ in either the European or Indian groups ( $p>0.05)$.
In the Chinese group, $\mathrm{P}$ and $\mathrm{A}+\mathrm{P}$ were significantly larger in the $>27$-year-old cohort compared to the <27-year-old cohort. $(\mathrm{p}<0.05)$

The following refers to the combination of 'all ages' measurements:

There is a significant difference in chord A between Chinese and European $(p<0.001)$ and between Chinese and Indian ( $p<0.001$ ), but no significant difference 
between European and Indian ( $\mathrm{p}>0.05)$. A is similar in size in European and Indian skulls, both being smaller than Chinese A.

There is a significant difference in chord $P$ between Chinese and Indian $(p<0.01)$ and between European and Indian ( $p<0.001$ ), but no significant difference between European and Chinese ( $p>0.05)$. $P$ is similar in size in European and Chinese skulls, both being larger than Indian P.

There is a significant difference in mandibular length between Chinese and Indian ( $\mathrm{p}<0.001$ ), and between European and Indian ( $p<0.05$ ), but no significant difference between European and Chinese ( $p$ >0.05). The mandibular length is approximately the same size in European and Chinese skulls, both being larger than in the Indian population.

There is no significant difference in $\mathrm{A} / \mathrm{A}+\mathrm{P}$ between Chinese and Indian ( $p>0.05$ ) but there is a significant difference between European and Chinese ( $p<0.001)$ and European and Indian $(\mathrm{p}<0.001)$

\section{DISCUSSION}

The present investigation compares material from three distinct populations, with the material from each group having a similar known or assessed age range and a similar range and degree of occlusal attrition patterns as described by Miles. ${ }^{27}$

A criticism of previous studies is that few authors state their sample selection and that the use of pooled multipopulation material can give results which may mask population differences. ${ }^{23,24}$ In the present study the three populations were well documented. The Chinese skulls were of known sex and age at death. Only four of the Chinese skulls were female. The sex of the Indian and European skulls was not known and it was therefore not possible to investigate sexual dimorphism.

Assessing age by attrition centres on the concept of functional age: in humans, the three permanent molar teeth erupt at intervals of approximately six years and this eruption sequence is constant. Difference in tooth tissue wear in teeth which erupt at different times provides information about the rate of tooth tissue wear. Miles established the rate of wear in young Anglo-Saxon skulls whose age could be determined from the state of development of their dentition. ${ }^{27}$ Assuming that this rate remained constant throughout life, he devised a system of ageing skeletal material based on the degree of molar wear. A study by Nowell verified the Miles method in the Tepe Hissar dental sample ${ }^{29}$ and Brothwell published a chart which uses a simple ordinal scoring system, based on Miles, to assist in aging skeletal remains from Neolithic to medieval times. ${ }^{30}$ Miles $^{31}$ was aware of the limitation of his method and it was concluded ${ }^{32}$ that the method was perhaps more appropriate if the investigator was interested in the mean age of a group of skulls.

The Chinese cohort is somewhat unique in that the ages were known from existing records. The sub-group of skulls from the Chinese group, with a known age range of 18 to 27 years, gave a mean age of approximately 21 years old and showed tooth tissue attrition that would be expected for that age group as shown on the Brothwell chart. Similarly, all skulls allocated to the group aged more than 27 years showed the expected degree of tooth tissue wear and none had attrition which did not match their true age. Based on this and the fact that other populations have been shown to exhibit age-related changes in patterns of tooth tissue attrition $^{33-35}$ it was considered appropriate, and within reason, to subdivide all three groups into young adults less than 27 years old and a more mature group whose ages were calculated as greater than 27 years old. The latter group would ensure that any measurements reflected a true population variation and would be less dependent on any growth dynamics.

The European skulls were either AngloSaxon (English) or from the Dark Ages (Scottish) and were chosen as they exhibited similar degrees of attrition and attrition patterns to the Chinese skulls. Miles ${ }^{31}$ postulated that rates of attrition in early European populations are considered to be reasonably constant from Neolithic to medieval times and the European group exhibited wear patterns similar to those described in another group of Anglo-Saxon skulls. It was therefore considered, with reasonable accuracy, to place the European skulls into two age groups using attrition charts based on Miles' original work. ${ }^{27}$ Following the same reasoning and with the same reservations, the Indian group was also allocated to two age groups.
Though proximal attrition was observed at all ages from 18 to 62 years old, in most skulls a definite proximal contact area between the first and second molar teeth had developed by the age of 27 years at death and this further strengthened the rationale of using this as a cut-off age in assessing the difference between younger skulls with relative little proximal wear and older skulls where anterior tooth drift could have resulted from age-related loss of proximal tooth tissue. Skulls with premortem tooth loss and proximal decay were eliminated from the present study.

Many authors have failed to state their measuring methods clearly, making interinvestigation comparisons meaningless. In agreement with Green ${ }^{11}$ the foramen was related either to the long axis of a mandibular tooth or to an interdental space, a convention well rooted in clinical practice. However, tooth loss, proximal decay or proximal attrition may cause mesial tooth drift, which were not considered in Green's study, though it was acknowledged that the relative position of the foramen would be influenced by these factors.

The present sample size was considered too small to assess if there was a population difference in mesiodistal tooth size before the occurrence of proximal attrition, however, the modal position of the foramen in older ( $>27$ years of age) Chinese and European skulls was located more distally when related to mandibular teeth, as would be expected from the mesial drifting of teeth due to attrition.

When the position of the mental foramen was considered in relation to standing teeth, irrespective of the age groups and cognisant of the fact that all skulls were at aged least 18 years at death, the results showed a distinct population difference in the foramen position. The modal position of the Chinese material was in the long axis of the second premolar tooth and this agreed closely with the results of Wang, ${ }^{10}$ Green ${ }^{11}$ and Santini. ${ }^{12}$ The modal position of the European material was more anterior, lying between the first and second premolar teeth and corresponded with the position normally cited in standard anatomy texts and with the results obtained by Kay. ${ }^{36}$ The commonly stated notion in standard anatomy texts, that is, that the foramen lies between the first and second premolars, may have arisen from studies 
of samples of early European material and is supported by the results of the present study. $51.5 \%$ of the in the Indian population is between the second premolar and the first molar, though $45.5 \%$ lies along the long axis of the second premolar. Al-Khateeb found, with advancing age, that there was an increase in the frequency of more posterior positioning of the mental foramen; ${ }^{15}$ this trend was seen in the present study though modal positions did not change with age except that in the >27-year-old Indian population it was in line with the long axis of the second premolar, with an additional $47 \%$ between the second premolar and first molar.

The results of the present study do not support the frequently cited view that the most common position of the mental foramen is in line with the longitudinal axis of the lower second premolar regardless of population. ${ }^{11}$

The method of Tebo and Telford ${ }^{2}$ was used in the present study to record the position of the mental foramen by relating it to fixed points on the body of the mandible. The symphysis menti, which is fused around six months after birth, was taken as the most convenient point of reference. This method places the mandible in Morrant's position defined as that which occurs when contact is made by the lower border of the corpus of the mandible when a vertical pressure is applied to the molar teeth. It is acknowledged that this position is affected by the curvature of the lower border of the corpus of the mandible, which can vary within genetically similar populations due to facial growth patterns. ${ }^{36}$ Bastir and Rosas ${ }^{37}$ have shown that the curvature of the inferior basal border differs considerably in dolichofacial and brachyfacial individuals, both of which occur within genetically similar populations. Additionally, geometric morphometric methods have shown that size importantly affects the position of the mental foramen at intra- and interspecific levels. ${ }^{38}$ The study reported that in one modern human population, larger size was linked with a relative forward shift of the foramen. The method used in the present study was nevertheless considered appropriate as the skulls were all from mature individuals and the age range in all three populations was relatively small, as were the calculated standard deviations of cords $\mathrm{A}, \mathrm{P}$ and length $\mathrm{A}+\mathrm{P}$.
The size of mandible is defined as the sum of two chord distances $(A+P)$. The anterior chord (A) is measured from the most anterior position of the anterior border of the foramen to the midline anterior at the symphysis menti. The posterior chord $(\mathrm{P})$ is measured from the most anterior position of the anterior border of the foramen to the point on the posterior border on the ramus at the level of the selected horizontal line. In the Chinese population, the $\mathrm{A}+\mathrm{P}$ was significantly larger $(p<0.001)$ in the older group and this was accounted for by an increase in distance from the mental foramen to the posterior border of the ramus of the mandible. There was no difference in the distance from the symphysis menti to the mental foramen and the ratio of $\mathrm{A} / \mathrm{A}+\mathrm{P}$ was also not significant. Once the permanent dentition has erupted, the mandible grows through posterior apposition of bone posteriorly, which would account for these observations.

There was no significant difference found between the younger and older groups in any of the distances or in the ratio of A/A + P in the European or Indian populations. Because there was generally no significant difference $<27$ years of age at death and $>27$ years of age at death (apart from the Chinese posterior distance), the results of the population have been analysed 'all ages' included.

In agreement with previous studies, ${ }^{2,10,12,39}$ Chinese and European mandibles have approximately the same overall length $(\mathrm{A}+\mathrm{P})$. In the Indian sample measured in the current investigation, $\mathrm{A}+\mathrm{P}$ was found to be smaller than both the European and Chinese. The distance from the symphysis menti to the mental foramen was similar in both European and Indian skulls and both these were smaller than the Chinese. However, the distance from the mental foramen to the posterior border of the ramus of the mandible is similar in the European and Chinese, both being larger than the Indian cohort.

To assess the real position of the mental foramen in the mandible, the ratio $\mathrm{A} / \mathrm{A}+\mathrm{P}$ was used. There was no difference between the Chinese and the Indian but there was a statistically significant difference $(\mathrm{p}<0.05)$ between the Chinese and European (smaller) and between the European and Indian (smaller).
Tebo and Telford ${ }^{2}$ stated that the foramen lies approximately one fourth of the distance from the symphysis menti to the posterior border of the mandible, which is smaller than that calculated by both Apinhasmit $(0.30)^{40}$ and Wang (0.27). ${ }^{10}$ The latter two studies are in virtual agreement with the current study which gave a ratio of 0.26 to 0.28 .

This ratio seems to remain stable regardless of population, age, or mandibular size, therefore it can be hypothesised that it is independent of the presence or absence of teeth, although no edentulous mandibles were studied. It appears to be a good and reliable method of locating the position of the foramen for mental block anaesthesia where malocclusion, absence of teeth or other reasons make it difficult to assess the correct location of the mental foramen.

The $\mathrm{A}+\mathrm{P}$ of European and Chinese mandibles are similar, though the mental foramen lies further forward in the European group. This holds true relative to its position to standing teeth and when the position is calculated as a ratio of measured distances $\mathrm{A} / \mathrm{A}+\mathrm{P}$.

The present results support the view that there is a true population difference in the position of the foramen in the three populations studied in the present investigation and the null hypothesis is rejected.

The variability of the position of the foramen should always be considered when diagnosing radiographic periapical areas and when undertaking periodontal or endodontic surgery in the area from the canine to the mesial root of the first molar. Population differences occur and it is clear that in Chinese people the most common position is in the long axis of the second premolar tooth.

Based on the present results it can be concluded that Indian and Chinese mandibles have the mental foramen in the same position relative to the size of the mandible, only that the Indian mandible is smaller.

Comparing the position of the mental foramen in European and Chinese mandibles, which are the same size, gives evidence of difference in position, as it is further forward in the European cohort. As well as being further forward relative to the position taken for the teeth, the position is further forward relative to 
the mandible itself, when contrasting the Chinese and European.

The anaesthetic technique for the mental block is usually based on the relationship of the mental foramen with premolar teeth. In light of our results and the population trend in the position of the foramen, it is suggested that the ratio $\mathrm{A} / \mathrm{A}+\mathrm{P}$ is more reliable to use. The foramen should be located around one quarter of the horizontal distance of the mandible.

The standard textbook notion that the mental foramen lies between the first and second premolars can no longer be accepted. Population differences occur and preoperative radiographs are mandatory. Additional radiographs should be taken at different angles, or other imaging techniques if necessary, before commencement of surgery.

1. Greenstein G, Tarnow D. The mental foramen and nerve: clinical and anatomical factors related to dental implant placement: a literature review. J Periodontol 2006; 77: 1933-1943.

2. Tebo H G, Telford I R. An analysis of the variations in position of the mental foramen. Anat Rec 1950 107: 61-66.

3. Hutchinson A C W. Dental and oral X-ray diagnosis. Edinburgh: E \& S Livingstone Ltd, 1954

4. Pendergrass E P, Pancoast H K, Hodes P J, Schaeffer J P. The head and neck in Roentgen diagnosis. Springfield: Thomas, 1956.

5. Grant J C B, Basmajian J V. Grant's method of anatomy. 7th ed. Baltimore: Williams \& Williams, 1965.

6. Last J R. Anatomy: regional and applied. 5th ed. London: Churchill Livingstone, 1972.

7. Crouch J E. Functional human anatomy. 2nd ed. Philadelphia: Lea \&t Febiger, 1972.

8. Lontric N. Foramen mentale. Morphological and topographical investigations. Excerpta Med 1956; 10: 236
9. Moss M L. A functional analysis of human mandibular growth. Am J Prosthet Dent 1960; 10: $1149-1160$.

10. Wang T M, Shih C, Liu J C, Kuo K J. A clinical and anatomical study of the location of the mental foramen in adult Chinese mandibles. Acta Anat (Basel) 1986; 126: 29-33.

11. Green R M. The position of the mental foramen: a comparison between the southern (Hong Kong) Chinese and other population and population groups. Oral Surg Oral Med Oral Pathol 1987; 63: 287-290

12. Santini A, Land M. A comparison of the position of the mental foramen in Chinese and British mandibles. Acta Anat (Basel) 1990; 137: 208-212.

13. Moiseiwitsch J R. Position of the mental foramen in a North American, white population. Oral Surg Oral Med Oral Pathol Oral Radiol Endod 1998. 85: 457-460

14. Aktekin M, Celik H M, Celik H H, Aldur M M, Aksit M D. Studies on the location of the mental foramen in Turkish mandibles. Morphologie 2003; 87: 17-19.

15. Al-Khateeb T, Al-Hadi Hamasha A, Ababneh K T. Position of the mental foramen in a northern regional Jordanian population. Surg Radiol Anat 2007; 29: 231-237.

16. Olasoji H O, Tahir A, Ekanem A U, Abubakar A A. Radiographic and anatomic locations of mental foramen in northern Nigerian adults. Niger Postgrad Med J 2004; 11: 230-233.

17. Igbigbi PS, Lebona S. The position and dimensions of the mental foramen in adult Malawian mandibles. West Afr J Med 2005; 24: 184-189.

18. Kim I S, Kim S G, Kim Y K, Kim J D. Position of the mental foramen in a Korean population: a clinical and radiographic study. Implant Dent 2006; 15: 404-411.

19. Shankland WE 2nd. The position of the mental foramen in Asian Indians. J Oral Implantol 1994; 20: 118-123.

20. Ngeow W C, Yuzawati Y. The location of the mental foramen in a selected Malay population. J Oral Sci 2003; 45: 171-175.

21. Mwaniki D L, Hassanali J. The position of mandibular and mental foramina in Kenyan African mandibles. East Afr Med J 1992; 69: 210-213.

22. Cutright B, Quillopa N, Schubert W. An anthropometric analysis of the key foramina for maxillofacial surgery. J Oral Maxillofac Surg 2003; 61: 354-357.

23. Gershenson A, Nathan $H$, Luchansky E. Mental foramen and mental nerve: changes with age. Acta Anat (Basel) 1986; 126: 21-28.

24. Phillips J L, Weller R N, Kulild J C. The mental foramen: 1. Size, orientation and positional relationship to the mandibular second premolar. J Endod 1990; 16: 221-223.

25. Green R M, Darvell B W. Tooth wear and the position of the mental foramen. Am J Phys Anthropol 1988: 77: 69-75.

26. Harrower G. A biometric study of one hundred and ten Asian small mandibles. Biometrika 1928; 20: 279-293.

27. Miles A E. Assessment of the ages of a population of Anglo-Saxons from their dentitions. Proc $R$ Soc Med 1962; 55: 881-886.

28. Morrant G M, Adyanthaya N K. A biometric study of the human mandible. Biometrika 1936; 28: 84-122.

29. Nowell G W. An evaluation of the miles method of ageing using the Tepe Hissar dental sample. Am J Phys Anthropol 1978; 49: 271-276.

30. Brothwell D R. Digging up bones. 3rd ed. Oxford: Oxford University Press, 1981.

31. Miles A E W. The dentition in the assessment of individual age in skeletal material. In Brothwell D R (ed) Dental anthropology. 9th ed. pp191-209. London: Pergamon Press, 1963.

32. Santini $A$, Land $M$, Raab $G M$. The accuracy of simple ordinal scoring of tooth attrition in age assessment. Forensic Sci Int 1990; 48: 175-184.

33. Murphy T R. The relationship between attritional facets and the occlusal plane in Aboriginal Australians. Arch Oral Biol 1964; 9: 269-280.

34. Akpata E S. Molar tooth attrition in a selected group of Nigerians. Community Dent Oral Epidemiol 1975; 3: 132-135.

35. Kieser J A, Groeneveld H T, Preston C B. Patterns of dental wear in the Lengua Indians of Paraguay. Am J Phys Anthropol 1985; 66: 21-29.

36. Enlow D H. Facial growth. Philadelphia: W B Saunders Company, 1990.

37. Bastir M, Rosas A. Facial heights: evolutionary relevance of postnatal ontogeny for facial orientation and skull morphology in humans and chimpanzees. J Hum Evol 2004; 47: 359-381.

38. Rosas A, Bastir M. Geometric morphometric analysis of allometric variation in the mandibular morphology from the hominids of Atapuerca, Sima de los Huesos Site. Anat Rec A Discov Mol Cell Evol Biol 2004; 278: 551-560.

39. Kay L W. Some anthropologic investigations of interest to oral surgeons. Int J Oral Surg 1974; 3: 363-379.

40. Apinhasmit W, Methathrathip D, Chompoopong S, Sangvichien S. Mental foramen in Thais: an anatomical variation related to gender and side. Surg Radiol Anat 2006; 28: 529-533. 